\title{
P I 4-05. Recruitment, retention and participation impact events among women participating in phase III community trial in
}

Thailand

\author{
P Pitisuttithum*1, S Rerks-Ngarm², J Kaewkungwal ${ }^{1}$, S Nitayaphan ${ }^{3}$, \\ C Khamboonruang ${ }^{4}$, P Kunasol ${ }^{4}$, P Suntharasamai ${ }^{1}$, MW Benenson ${ }^{5}$ and \\ $\mathrm{JH} \mathrm{Kim}^{5}$
}

Address: ${ }^{1}$ Clinical Tropical Medicine, Faculty of Tropical Medicine, Mahidol University, Bangkok, Thailand, ${ }^{2}$ Department of Diseases Control, Ministry of Public Health, Bangkok, Thailand, ${ }^{3}$ Armed Forces Research Institute of Medical Sciences Thai component, Bangkok, Thailand, ${ }^{4}$ Department of Disease Control, Ministry of Public Health, Bangkok, Thailand and ${ }^{5}$ Armed Forces Research Institute of Medical Sciences U.S. component, Bangkok, Thailand

* Corresponding author

from AIDS Vaccine 2009

Paris, France. 19-22 October 2009

Published: 22 October 2009

Retrovirology 2009, 6(Suppl 3):PI93 doi:10.1 186/I742-4690-6-S3-PI93

This abstract is available from: http://www.retrovirology.com/content/6/S3/PI93

(c) 2009 Pitisuttithum et al; licensee BioMed Central Ltd.

\section{Background}

Participation of women is considered necessary in HIV vaccine trials. However, recruitment, decision process, retention and participation impact events may differ from men. The trials also require that pregnancy and breastfeeding be avoided, and this may put pressure on participants, especially when the study is conducted in sexually active women aged $18-30$ years.

\section{Methods}

Randomized, double-blind placebo controlled trial involving eligible volunteers 18 -30 years old of a primeboost HIV vaccine. The study has completed enrollment and vaccination and is now in the follow up phase. General demographic characteristics, reasons for enrolment, follow up rate and participant impact events (PIE) in women were analyzed.

\section{Results}

6334 out of 16402 (38.6\%) participants were female. $66 \%$ were married. $20 \%$ were single, and the rest were divorced, widowed or separated. $33 \%$ had primary education, and $65 \%$ had junior secondary or higher education. Only $2 \%$ reported of no education. $76 \%$ were employed; $12 \%$ were unemployed; and $12 \%$ were housewives.
4.34\% became pregnant during the initial 7 months period after first vaccination. The retention rate among women was high. There was no significant difference in withdrawal rate between males and females $(\mathrm{p}=0.17)$. $4.6 \%$ (297) of women reported PIE which is significantly different from men $(\mathrm{p}<0.01)$. Marital status was significantly associated with PIE among woman with PIE ( $\mathrm{p}<$ 0.01). 85.2\% of PIE were related to personal relationship problems, and almost all PIE (92.4\%) were resolved satisfactorily. $17.4 \%$ of women reporting a PIE withdrew from participation in spite of satisfactory resolution of the PIE.

\section{Conclusion}

The phase III trial successfully enrolled women (38.6\%). They were well educated and typically employed. The pregnancy rate is reasonable when compared to other vaccine trials. Married women reported higher rates of PIE than other groups. Resolution of PIEs was satisfactory in most cases. 